\title{
Alguns Conceitos de Loucura entre a Psiquiatria e a Saúde Mental: DiÁlogos entre os Opostos? ${ }^{1}$
}

\author{
Francisco da Costa Júnior ${ }^{2}$ e Marcelo Medeiros ${ }^{3}$ \\ Universidade de Brasília (UnB) \\ Universidade Federal de Goiás
}

\begin{abstract}
Este artigo apresenta parte dos resultados de uma pesquisa bibliográfica sobre os conceitos de loucura na Psiquiatria e na Saúde Mental. Foram analisadas publicações indexadas na base de dados LILACS entre 1999 e 2004. A pesquisa mais ampla foi feita por áreas temáticas e, no presente artigo, nos concentramos em duas delas: as que afirmam conceitos de loucura como doença médica e as que definem loucura rejeitando explicitamente a concepção psiquiátrica de loucura, mas o fazem discutindo a loucura baseadas em concepções que mantêm diálogo com os objetos perceptivos (diagnósticos descritivos) que a Psiquiatria concebeu ao longo de sua história. Estas últimas conceituações, que por vezes são chamadas de alternativas mas freqüentemente são anteriores aos conceitos atuais da Psiquiatria (da loucura como doença genética, por exemplo), apontam construtos teóricos que afirmam uma concepção de mente (de psicológico) desde um modo mais individualizado até como algo resultante das inter-relações sociais. Discute-se, por fim, como esses conceitos de loucura fazem parte de concepções de mundo (e, conseqüentemente, de ser humano) distintas e mesmo mutuamente excludentes em relação aos conceitos propriamente psiquiátricos, sendo que há uma visão de mundo mais naturalista na Psiquiatria e, na Saúde
\end{abstract}

1 Este artigo é integrante da dissertação de mestrado "A conceituação de loucura na psiquiatria e na saúde mental: um estudo de revisão", apresentada junto à Faculdade de Ciências da Saúde da Universidade de Brasília em 2005, sob orientação do Prof. Dr. Marcelo Medeiros.

2 Ambulatório de Saúde Mental do Hospital Universitário de Brasília (HUB) - Universidade de Brasília (UnB). Endereço eletrônico: fjcosta@unb.br.

3 Faculdade de Enfermagem da Universidade Federal de Goiás. Endereço eletrônico: marcelo@fen.ufg.br. 


\title{
Francisco da Costa Júnior e Marcelo Medeiros
}

\author{
Mental, uma visão mais sociológica e coletivista, e elas têm entrado em \\ choque para além das problematizações teóricas em torno da loucura. \\ Descritores: Loucura. Saúde mental. Psiquiatria.
}

\section{Introdução}

O presente artigo busca discutir os conceitos de loucura das instituições de saber Psiquiatria e Saúde Mental. Parte-se do pressuposto de que tais instituições, embora cultivem práticas contemporâneas de lida com a loucura, podem ser consideradas dois campos discursivos distintos. $\mathrm{E}$ isso se dá da seguinte maneira: 1) ambas numa só ação social, trabalhando de modo complementar; 2) como duas ações com fins e meios distintos (e por isso antagônicas política e ideologicamente); 3) como dois campos de saber prático que legitimam várias ações que têm sido política, ideológica e cientificamente reunidas em torno dessas instituições, que, então, de algum modo, se interpenetram ou antagonizam.

Consideramos esses três modos de conceber a relação entre Saúde Mental e Psiquiatria como sendo "verdadeiros" a depender do ponto de vista de quem os analisa; aqui, partiremos para a compreensão do que a Saúde Mental está concebendo como loucura nos atendo à terceira das possibilidades enumeradas. $\mathrm{O}$ mais correto seria chamarmos o que aqui estamos designando genericamente como Saúde Mental de Atenção Psicossocial em Saúde Mental, conforme o que está sendo estruturado pela reforma psiquiátrica brasileira e teorizado principalmente pela Enfermagem, a Psicologia, a Terapia Ocupacional e por algumas dissidências da Psiquiatria biológica, hegemônica na atualidade - já que Saúde Mental pode ter uma abrangência difusa, a depender do país em que se formula e da orientação política, ideológica e profissional de quem a descreve. Para efeitos do que segue, referiremos Saúde Mental tãosomente, tendo em vista que nenhuma outra designação garantiria a superação dos problemas de definição do campo.

Desse modo, incluiremos em nossa análise sobre os conceitos de loucura o que a Psiquiatria tradicional concebe como sendo loucura, pois consideramos que esta é parte fundamental das teorizações atuais em áreas do 
Alguns Conceitos de Loucura entre a Psiquiatria e a Saúde Mental: Diálogos entre os Opostos?

saber que antagonizam com a Psiquiatria - se não propriamente aceitando como válidas todas as conceituações psiquiátricas, ao menos se opondo a elas ou, principalmente, interpretando-as como parte dos problemas que a loucura na atualidade levanta, para além do indivíduo considerado louco. Ou seja: no mínimo, a Psiquiatria (como teoria e prática) torna-se um objeto de estudo de parte da Saúde Mental, principalmente quando esta faz uma análise histórica e sociológica em busca de compreender a loucura.

O presente artigo busca, portanto, apreender o que a Saúde Mental entende por loucura, atendo-se ao diálogo com a área da Psiquiatria, que se dá em alguns momentos por concordância, em outros por assimilação ou, mais frequientemente, por oposição - fundamentalmente da Saúde Mental em relação às concepções de loucura na Psiquiatria clássica, clínica ou biológica (que estamos chamando aqui de tradicional). Nos deteremos, então, nas conceituações atuais de loucura na Saúde Mental que parecem, em princípio, mais próximas das conceituações propriamente psiquiátricas, embora muitas vezes se auto-afirmando e mesmo teorizando dentro de um modelo que rejeita a Psiquiatria, pretendendo-se uma superação dela (Basaglia, 1979).

Não consideramos, de forma alguma, que a pesquisa deste artigo esgote os conceitos atuais de loucura na Saúde Mental contemporânea. Deixaremos, por questões editoriais, uma parte fundamental de tais conceituações para uma outra oportunidade; aqui, buscaremos uma apreciação daquilo que consideramos que a Saúde Mental faz de modo mais característico em seu campo de saber, que é buscar conceber a loucura e agir sobre ela percebendo-a como fenômeno histórico-social.

Assim, nosso objetivo geral é a apreensão do conceito de loucura na pesquisa em Saúde Mental, porém, considerando a abrangência e a complexidade da conceituação de loucura como esquizofrenia na Psiquiatria e a relação que a Saúde Mental estabelece com esse campo, optamos pelo seguinte objetivo específico: identificar e analisar as concepções de loucura na interface Psiquiatria / Saúde Mental, debatendo as possíveis repercussões dessa interface sobre a teorização desta última como prática ativa na reforma psiquiátrica.

Utilizamos, como base para este ensaio, uma pesquisa bibliográfica de metodologia qualitativa, desenvolvida sobre material elaborado cientificamente, de modo que executamos uma abordagem exploratória de fontes bibliográ- 
ficas (Gil, 2002). Elas foram selecionadas entre os textos indexados na base de dados LILACS (Literatura Latino-Americana e do Caribe em Ciências da Saúde, por meio da Biblioteca Virtual em Saúde - BVS, no endereço eletrônico www.bireme.br) no período de 1999 a setembro de 2004. Pesquisamos a partir dos seguintes termos, presentes nos títulos ou no descritor de assunto:

Loucura, locura, madness e lunacy

Louco, loco e lunatic

Psicose, psicosis e psychosis

Psicótico, psicópata e psychotic

Esquizofrenia e schizophrenia

Esquizofrenico e schizophrenic

Psicopatología e Psychopathology

Doença mental, enfermidad mental e mental illness

Saúde mental, salud mental e mental health.

Passamos, então, à leitura dos artigos assim selecionados, com vistas a identificar os que se referiam a conceitos de loucura direta ou indiretamente. Nesse segundo passo, selecionamos os artigos de acordo com a sua emissão de conceitos para as categorias temáticas que se relacionam à conceituação de loucura conforme pressupostos de Bardin (2002) para a análise de conteúdo por modalidade temática.

\section{Conceitos de loucura e concepções de humano na Psiquiatria e na Saúde} Mental

Não há razão para ocultar as contradições que o debate científico tem gerado em torno do tema loucura (Pessoti, 1999), por isso selecionamos os artigos de modo a não excluir aqueles que talvez não sejam considerados pro- 
Alguns Conceitos de Loucura entre a Psiquiatria e a Saúde Mental: Diálogos entre os Opostos?

priamente de Saúde Mental por utilizarem métodos e apontamentos teóricos ou terem objetivos que se opõem à intencionalidade, como campo de saber e prática institucional político-ideológica, da reforma psiquiátrica brasileira (Amarante, 1994; Basaglia, 1979). Logo, não desconsideramos os artigos que tratam da teorização de esquizofrenia pela Psiquiatria biológica ou clínica, e os inserimos dentro do campo da Saúde Mental, mesmo sendo esta teorização considerada não-válida por muitos pesquisadores da Saúde Mental mais críticos à Psiquiatria, ou por aqueles que são muito comentados nessa área (Szazs, 1978) - da mesma forma que uma revisão teórica da Psiquiatria biológica sobre esquizofrenia desconsideraria boa parte dos autores "reformistas", por entender suas afirmações como cientificamente não-válidas.

Com base nisso, estabeleceram-se três grupos temáticos principais:

1. Conceitos de loucura como doença psiquiátrica - em especial como psicose e esquizofrenia; conceitos aos quais não nos ateremos aqui, embora sejam objeto de análise da mesma dissertação de mestrado.

2. Conceitos de loucura na interface doença psiquiátrica tradicional / modificação e crítica dos conceitos psiquiátricos pela Saúde Mental - incluindo conceitos psicológico-filosóficos de loucura, os quais estabelecem uma área de interpenetração entre a Psiquiatria e a Saúde Mental. Sobre este grupo recairá o foco de análise deste artigo.

3. Conceitos histórico-sociais de loucura relacionados à institucionalização psiquiátrica. Talvez seja este o campo de teorização que faz mais justiça às intenções de boa parte dos pesquisadores que se dedicam à Saúde Mental como campo de saber autônomo e independente, em superação ao campo psiquiátrico no que diz respeito à produção de conhecimento e mesmo à sua teorização como integrante da própria institucionalização da loucura (Amarante, 1994). Mas essa categoria não será analisada no presente artigo, uma vez que sua importância e complexidade requerem análise futura, em que seja foco.

Uma apreciação prévia do título do segundo agrupamento temático poderia nos dizer que a Saúde Mental atualiza conceitos de loucura que fizeram parte da história conceitual da Psiquiatria mas atualmente são considerados conceitos equivocados, tendo sido superados pela produção científica psiquiátrica mais recente. Esta é, em parte, a nossa hipótese inicial, desde que 


\section{Francisco da Costa Júnior e Marcelo Medeiros}

seja observada de um ponto de vista psiquiátrico. Contudo, pretendemos um ponto de vista como o mencionado por David Cooper (1989) quanto à psicanálise, um ponto de vista que permite a muitos autores e profissionais que iniciem sua compreensão mais complexa da loucura com a ferramenta teórica que têm à mão. Assim, modificando a primeira formulação, nossa hipótese é que as concepções de loucura muito dependem da visão de mundo e da moralidade (quais ações são consideradas "certas", "boas" pelo modelo) que um dado suporte teórico fornece ou que é adequada ao pesquisador quando este dirige sua intencionalidade para a loucura; e que os diálogos entre Psiquiatria e Saúde Mental se fazem dentro de uma gama de possibilidades a depender do enlace que ambas têm com as mesmas fontes teóricas ou com fontes teóricas semelhantes - o que transforma a discussão em torno de conceitos de loucura em um debate no campo da Filosofia da ciência, e mesmo da Filosofia moral.

Nesse sentido, pressupomos que há um diálogo entre Psiquiatria e Saúde Mental no que tange aos conceitos de loucura, mas que tal diálogo, em termos não ideológico-institucionais, se torna uma rivalização à medida que as concepções de humano das duas áreas se afastam, entre o pólo naturalista da Psiquiatria e o pólo das Ciências Humanas e Sociais na Saúde Mental, até quase ao ponto de constituírem "duas culturas diferentes": uma permeada pela concepção de mundo das ciências naturais, e a outra permeada pela concepção de mundo das ciências humanas, como defende Snow (1995). Dito de outro modo, há entre Psiquiatria e Saúde Mental significativas diferenças ontológicas (Castoriadis, 1999), as quais aumentam ou diminuem à medida que as concepções de humano se aproximam ou se afastam, conforme ambas as áreas se abasteçam ou não das mesmas fontes teóricas. ${ }^{4}$

Partimos, agora, para a análise dos 38 textos que foram selecionados nos dois agrupamentos temáticos que estudamos neste artigo.

4 Ontologia, aqui, conforme Castoriades (1999), engloba uma dada visão de mundo e concepção de humano, bem como a inserção dotada de sentido deste humano em tal construção simbólica de mundo (Cassirer, 2005). O termo também pode ser entendido, embora de um modo simplista e fragmentado, como paradigma, conforme Kuhn, 2005. Essa noção de paradigma propiciou a percepção de que suas teorias (em busca da verdade científica que as coisas teriam se discriminadas em suas leis naturais) estão impregnadas de concepções apriorísticas subjetivas, o que contribuiu para um maior diálogo entre as áreas mais naturalistas (como são a Medicina e boa parte das áreas relacionadas à saúde) e as Ciências Humanas. 
Alguns Conceitos de Loucura entre a Psiquiatria e a Saúde Mental: Diálogos entre os Opostos?

\section{Conceitos de loucura como doença psiquiátrica}

Todos os artigos analisados oriundos de publicações psiquiátricas (com corpo editorial formado por psiquiatras) tratam a esquizofrenia como entidade nosológica autônoma em relação à intencionalidade humana: uma doença médica, de caráter biofísico, ou orgânico puro, que a Psiquiatria esclareceu e esclarece no senso comum, a partir das concepções populares de loucura. Todos esses artigos tratam da esquizofrenia como fenômeno de existência real, um fenômeno patológico da estrutura bioquímica do cérebro, embora havendo divergências sobre a sua essência fisiopatológica, a sua origem (etiologia) e a ação adequada, do ponto de vista médico, a adotar (sua terapêutica) - exceto pelo uso de drogas antipsicóticas, que é unanimidade.

Discutem-se pequenas variações quanto às classificações mais adequadas sobre a esquizofrenia (Dias \& Dalgalarrondo, 2001; Sallet \& Gattaz, 2002), mas com todos os trabalhos aceitando a classificação atual do DSM (American Psychiatric Association, 2002) e do CID (Organização Mundial da Saúde, 1993) como válidas, por representarem uma evolução científica que a Psiquiatria construiu ao longo de mais de 200 anos (Elkis, 2000; Lopes, 2001).

Contudo, Lopes (2001) reitera que, historicamente, loucura (como reconhecida no senso comum) tornou-se conceituada como psicose no fim do século XIX e início do século XX. Mas depois, ao longo do século XX, "psicose propriamente dita fica sendo a esquizofrenia" (indicar a página da citação). Ou seja, esquizofrenia, fenomenologicamente percebida, é a definição da mais típica das psicoses, a psicose padrão. E Lopes (2001) também acrescenta que "a loucura descrita pelos trágicos gregos, a loucura descrita na bíblia, é a mesma loucura de hoje, do homem que mora em apartamento em qualquer cidade do mundo. Psicose [é] igual a loucura" (indicar a página da citação) ${ }^{5}$. Disso conclui-se que, tanto no sentido historicamente estabelecido quanto na configuração atual, é trabalho da Psiquiatria elucidar o senso comum, que supostamente vê a loucura de forma distorcida (Villares, Redko, \& Mari, 1999), sendo trabalho da Psiquiatria mostrar o que há de verdade na loucura, ou seja, a psicose esquizofrênica, uma doença que a Psiquiatria tem conhecimento médico para perceber e tratar de modo científico.

5 José Leme Lopes proferiu esta conferência em 1988, que, transcrita em formato de ensaio em 2000, foi submetida à revisão do psiquiatra Paulo Delgalarrondo 


\section{Francisco da Costa Júnior e Marcelo Medeiros}

Uma concepção completa sobre a loucura como doença não é encontrada em um único texto ou autor. Segundo Stone (1999), um psiquiatra historiador da Psiquiatria, a "era dos livros-texto de um único autor estava chegando ao fim" já na década de 1960. Nesse sentido, vemos os artigos atuais se ocuparem da teorização psiquiátrica de modo super-especializado, cada autor se atendo a um componente da esquizofrenia conceituada como doença. Muitos afirmam a genética da esquizofrenia (Cordeiro Júnior, Junqueira \& Vallada, 2001; Lima, 1999; Ojopi, Gregório, Guimarães, Fridman, \& Dias Neto, 2004; Samaia et al., 1999), associada a "fatores de risco" ou "ambientais" em sua etiologia (Messas, 2000; Vallada \& Samaia, 2000). Outros afirmam categoricamente achados estatísticos bioquímicos, eletrofisiológicos e por exames de imagem como sendo aspectos somáticos da fisiopatologia da esquizofrenia (Basile, 2000; Bressan, Bigliani, \& Pilowsky, 2001; Busatto Filho, 2000; Elkis, Kimura, \& Nita, 2001; Gattaz, 2000; Gilbert \& Keshavan, 2001; Marchetti, 2000), alguns denotando mais claramente que tais apontamentos são somente hipóteses somáticas para uma possível patogenia da esquizofrenia como doença orgânica (Bressan \& Pilowski, 2003; Lara \& Souza, 2001).

Um grupo menor discute ou propõe teorizações sobre mecanismos estritamente psicológicos para a conformação dos sintomas percebidos na clínica da esquizofrenia ou do psicótico, sem discutir se há e qual seria a relação deste puramente psíquico com o somático ou com algo além do psíquico individual (Alho Filho, 2000; Martins, Costa, \& Aquino, 1999; Souza, 1999). Estes, portanto, buscam uma melhor explicação da psicopatologia da psicose/esquizofrenia como fenômeno psíquico puro e individual. Afirmam como auxílio metodológico em seus projetos de conceituação a Filosofia analítica sobre a linguagem, a Fenomenologia da mente ou a Psicanálise. Divergindo dessa concepção, Adad, Castro e Mattos (2000) afirmam achados estatísticos em testes neuropsicológicos como resultantes da esquizofrenia, numa concepção de mente que coloca o psiquismo humano como oriundo do somático.

Vários outros estudos (às vezes os mesmos, ao revisarem hipóteses psicológicas para a esquizofrenia) interpõem a psicopatologia apenas como o meio diagnóstico, via observação dos fenômenos psíquicos que permitiriam acesso perceptivo às alterações biofísicas na esquizofrenia, cujas causas (ou como a maioria dos artigos refere, cujos fatores "precipitadores" ou "desenca- 
Alguns Conceitos de Loucura entre a Psiquiatria e a Saúde Mental: Diálogos entre os Opostos?

deantes" de surto) podem ser os mais variados, apontados como hipóteses ou como possíveis fatores de risco (ambientais): maconha (Soares-Weiser, Weiser, \& Davidson, 2003; Witton \& Murray, 2004), "possível interação medicamentosa de sibutramina com finasterida" (Sucar, Sougey, \& Brandão Neto, 2002); "anorexígenos, fluoxetina e sertralina" (Souza, Marmorato, Castel, \& Gattaz, 1999) e gravidez (Silva, Polanczyk, \& Millán, 2000).

\section{Conceitos de loucura na interface doença psiquiátrica tradicional/ modificação e críticas dos conceitos psiquiátricos pela Saúde Mental}

Um número considerável de artigos se concentra numa teorização psicanalítica como modo de esclarecer a loucura. Tais artigos referem-se a psicose, esquizofrenia e autismo, partindo da existência desses conceitos por terem sido eles "purificados cientificamente" a partir de um amplo espectro popular de loucura, oriundos da Psiquiatria tradicional.

Santos (1999) teoriza sobre a psicanálise segundo Winnicott, no que este teria contribuído para uma compreensão e uma terapêutica de pacientes psicóticos. Santos afirma a psicose como uma falha entre o ambiente (relações parentais, principalmente) e o sujeito no decurso do desenvolvimento psíquico individual; ou uma falha desenvolvimental que ocorreria em nível mais primitivo ou regressivo que os conflitos emergentes na neurose. A psicose, segundo ele, "leva até os estágios mais primitivos do desenvolvimento e da organização da mente, quando ainda não se fixou uma diferença nítida entre o self e o não-self.... A psicose está ligada à privação emocional em um estágio anterior àquele em que o bebê possa perceber esta privação ..., já que ele se encontrava em um estágio evolutivo que ainda não o capacitava a se diferenciar minimamente do ambiente ..., ocasionando uma incapacidade absoluta de se relacionar com objetos". Desse modo, "as falhas do ambiente favorável levam a esse comprometimento da evolução da personalidade e do self do indivíduo, cujo 'resultado é chamado esquizofrenia"' (pp. 618-620).

Também por um prisma psicanalítico, mas a partir de Jacques Lacan, Freire (1999) atualiza, entre outras coisas, a teoria lacaniana da psicose. Nesta, o material psíquico 


\title{
Francisco da Costa Júnior e Marcelo Medeiros
}

\begin{abstract}
que não veio um dia no simbólico, ou seja, o foracluído, o não inscrito, reaparece como exterior à realidade psíquica. Lacan precisa que esse foracluído não se refere a qualquer representação da realidade, mas ao que constitui esta realidade como simbólica, a saber, o Nome do Pai (...), o operador que separa, que barra a relação da criança com a mãe, permitindo à criança vir a significá-la. (p.569)
\end{abstract}

Desse modo, "a foraclusão do Nome do Pai circunscreveria o domínio do que subsiste fora da simbolização, isto é, a estrutura da psicose", o que faz o paciente psicótico permanecer "imobilizado numa posição que o coloca sem condições de restaurar o sentido que testemunha, e de partilhá-lo no discurso dos outros" (p. 569).

Outro trabalho psicanalítico sobre psicose em criança (Reis, 2000) nos mostra com alguma clareza a relação do conceito (ou dos conceitos) de loucura na Psicanálise dialogando com os conceitos psiquiátricos; e simultaneamente os apreendendo como objeto perceptivo (teórico) e, depois, deles se afastando numa nova elaboração que se distancia da teorização psiquiátrica. Afastamento posterior, no qual se afirma uma aproximação com a antipsiquiatria.

Antes de iniciar uma discussão de caso psicanalítica, na qual está em jogo se uma dada criança é psicótica ou neurótica, também com apoio teórico em Jacques Lacan, Reis (2000) introduz um breve histórico da Psiquiatria teorizando e tratando a loucura, ao final do qual aponta onde estaria inserida a discussão de caso que depois faz:

Para a psiquiatria, que pensa a loucura como uma doença, um desvio, a cura seria na direção de uma maior adaptação do sujeito à sociedade. Enquanto, para a psicanálise, a preocupação seria, se assim posso dizer, adaptar o sujeito a si mesmo, a seu self.... A sociedade, com toda a paz de sua consciência, confia no médico para que este designe os indivíduos a serem excluídos por meio de um diagnóstico, quando não é mais possível integrá-los, custe o que custar, à "normalidade" - sem se perguntar absolutamente sobre os significados dessas loucuras ou desses retardamentos.... Essas são palavras da psicanalista francesa Maud Mannoni que aplicou as idéias de Lacan à psicopatologia de crianças, articulando-as também com o movimento da antipsiquiatria (Laing \& Cooper). Poderíamos dizer que é lacaniana enquanto orientação teórica e quanto à prática está bem perto das posições anti-psiquiátricas. (Reis, 2000, p. 216)

Com base em outra visão psicanalítica - da Psicologia analítica, segundo Carl Gustav Jung -, Ramos (2001) apresenta sua teorização da loucura como 
Alguns Conceitos de Loucura entre a Psiquiatria e a Saúde Mental: Diálogos entre os Opostos?

restrita ao plano psicológico, em diálogo das teorias de Jung com o conceito originalmente psiquiátrico de esquizofrenia: segundo a autora, "Jung defendeu que a esquizofrenia era tratável e curável através de métodos psicológicos" (p. 85).

A autora também põe sua teorização da Psiquiatria: “o tratamento psiquiátrico tradicional contribui para cronificação das doenças mentais". Historicizando Jung, ela afirma que "Freud introduziu a dimensão psicológica na psiquiatria", o que teria sido de influência fundamental sobre Jung, já que, em 1906, "Jung refuta a concepção anatômica dos processos psíquicos, que considera todos os processos psíquicos correlatos de processos celulares". Contrariando isso, Jung teria começado a utilizar-se de técnicas de acesso ao psíquico profundo (inconsciente) em pacientes que vinham sendo considerados esquizofrênicos de "prognóstico ruim" pela Psiquiatria. Para ilustrar sua discussão, Ramos (2001) relata um caso em que, "após a interpretação de Jung, a paciente teria trazido material inconsciente a sua consciência", de modo que "15 dias mais tarde saiu do asilo para não mais voltar". Jung, a partir daí, "estudava permanentemente o universo interior do doente mental", o que o levou a "uma primeira idéia quanto às origens psíquicas da esquizofrenia":

Debruçando-se sobre os doentes e seus destinos, compreendeu que os delírios e as alucinações se constituem em torno de um núcleo significativo. Os sintomas psicóticos espelham o drama de uma vida, suas esperanças, seus desejos. (...) No fundo não descobrimos na doença mental nada de novo e desconhecido; mas a base mesmo de nossa própria natureza. (Ramos, 2001, p. 88)

Outro artigo, que se refere à reforma psiquiátrica no Chile, descreve e defende "uma estratégia psíquica dinâmica de tratamento da psicose" (Riquelme Véjar \& Arancibia Vaccaro, 2002, p. 40). Propõem os autores uma "reabilitação como tarefa indispensável no trabalho com pacientes psicóticos", o que tem "implicado diversas reformas assistenciais, fundadas na crítica da atenção tradicional, que em séculos passados deu respostas ao tratamento asilar da psicose". Entendendo que para a inserção social do psicótico é necessário "levar em consideração a natureza da psicopatologia da psicose", os autores defendem que, em centros de atenção intermediária (centros diurnos, hospitais-dia), é necessário uma terapêutica que possibilite ao paciente sair de sua posição "autista", de isolamento e retraimento afetivo, "uma modalidade própria da psicose, cuja manifestação essencial é o movimento de desinvesti- 
dura do mundo exterior como meio de proteger-se de um encontro com o real, vivenciado como perigoso e catastrófico para a integridade psíquica". A partir daí, os autores associam o processo terapêutico de reabilitação com alguns passos da Psicanálise que se baseia na teoria das relações objetais, como forma de a equipe se relacionar com o psicótico. Nesse processo, o psicótico passaria por estágios de inter-relações com a instituição, os quais teriam a função de revivenciar momentos de seu desenvolvimento psíquico, que o teriam deixado com falhas básicas em sua estrutura psíquica individual.

Podemos afirmar, diante desse conjunto de trabalhos, que os conceitos de loucura que têm base psicanalítica se aproximam dos conceitos psiquiátricos tradicionais (que definem a loucura como doença orgânica), se não aceitando toda a conceituação nosológica psiquiátrica atual, ao menos aceitando os seus conceitos perceptivos, os conceitos nosográficos, ou de rotulação classificatória descritiva, como os de psicose e de esquizofrenia. São dadas a esses conceitos nosográficos (ou lhes são resgatadas) "novas" explicações teóricas que os definem, em essência, de um outro modo - por uma teorização não mais reconhecida como sendo propriamente psiquiátrica.

O mesmo pode ser feito utilizando-se outras construções teóricas, desde que deslocadas para explicar em essência o fenômeno perceptivo (descritivo) da loucura, da psicose ou da esquizofrenia - a depender de até que ponto se rejeita a teorização psiquiátrica tradicional e se aceita uma nova conceituação essencialista dos fenômenos que a Psiquiatria rotulou.

Assim pode ocorrer com a Psiquiatria - ou seria Saúde Mental? - teorizando sobre a loucura por intermédio de conceitos da Antropologia, como vemos no estudo de caso de Fierro Urresta et al. (2003). Neste, um "paciente com sintomas claramente psicóticos" serve de exemplo para teorizações antropológicas sobre a loucura - embora sem qualquer questionamento do conceito de psicose e da estrutura terapêutica que o envolve.

Sobre o referido paciente psicótico conta-se que apresentou delírios e alucinações acerca de seu irmão recém-falecido, que o estaria "possuindo" espiritualmente e o levando a ações contrárias a sua vontade. Tais "possessões" ocorreram até que o paciente se auto-agrediu numa tentativa de ferir o coração e com isso livrar-se do irmão que o "possuía". Em seguida, os autores relatam que a família, ao ser analisada, apresentava um "sistema de crenças" próprio, 
Alguns Conceitos de Loucura entre a Psiquiatria e a Saúde Mental: Diálogos entre os Opostos?

que começou a se manifestar com a morte do irmão. A partir disso, outros irmãos, pais e sobrinhos do paciente passaram a sentir a presença do falecido, acreditando todos que ele estava sempre na casa, de modo que os familiares vez ou outra percebiam rapidamente sua presença ou sentiam estarem sendo possuídos por ele. Segundo os autores, essa crença coletiva teria ocorrido até que o paciente tornou-se "possuído" ininterruptamente, indo parar no hospital com o ferimento auto-infligido.

A partir do relato, Fierro Urresta et al. (2003) citam conceitos da Antropologia; apoio teórico que lhes permite chegar à conclusão de que é característica humana ter um sistema de crenças, "um conjunto de conceitos gerais que governam nossa visão de mundo e nossa atividade nele (...), que vão servir de substrato para selecionar e interpretar as experiências vividas". Descrevem esse sistema de crenças, em seguida, como um pensamento mágico que é "patrimônio do funcionamento cognitivo dos seres humanos e não está restrito aos povos denominados selvagens, aos pacientes psicóticos e às crianças". Mesmo ao contrário, na evolução da espécie humana, "graças à existência de uma mente flexível também foi possível ter a magia como temática para explicar o que acontece" (Fierro Urresta et al., 2003, p. 288).

Com essa concepção de sistemas de crenças coletivo, que pode constituir-se essencialmente de um modelo explicativo mágico sobre os fenômenos do mundo, afirmam os autores que o paciente "desenvolveu uma sintomatologia claramente psicótica ao redor da qual o único fator desencadeante parece ser a posta em marcha, no grupo familiar que o cercava, de um conjunto de crenças mágicas". Pelo poder e a força desse pensamento mágico de toda a família, e passando por luto pela perda de um ente próximo - no qual seria habitual a ocorrência de familiares que "experimentam a presença do morto mediante a presença de imagens visuais, sons, cheiros e sensações táteis", até que desapareçam paulatinamente -, a família do paciente deu uma interpretação particular, mágica, a essas experiências. Essa interpretação teria influenciado sobremaneira o paciente, que veio a sentir que o espírito do irmão lhe havia adentrado, provocando "grande terror". Daí em diante "tudo estava disposto para que em seu corpo sucedesse o mais estranho e inesperado", para o que contribuiu o poder da crença que o resto da família tinha sobre ele, deixando de vê-lo como um sujeito autônomo, livre e vivo, e passando a considerá-lo "objeto de temores e proibições". 


\title{
Francisco da Costa Júnior e Marcelo Medeiros
}

\begin{abstract}
Segundo Levi-Strauss, neste instante a integridade física (e mental) não resiste à dissolução da personalidade social. Daqui em diante e prisioneiro de uma intensa ansiedade, ele apenas podia opor uma ligeira resistência. Seu corpo já solitário era cenário das experiências mais estranhas que ele já havia tido. Podemos nos atrever a dizer que neste instante se iniciou a psicose? Esse foi o momento em que uma crença compartilhada e aceita em seu entorno se transformou em idéia delirante? $\mathrm{Na}$ atualidade, não dispomos de conhecimento suficiente para nos atrevermos a responder afirmativamente a estas perguntas (Fierro Urresta et al., 2003, p. 291).
\end{abstract}

Embora não discutam quais repercussões teorizações como essas trazem para o conceito de loucura, essas ponderações deixam entrever que a crença coletiva pode interpretar fenômenos de um modo mágico, de forma tão poderosa que a auto-crença do sujeito o deixa em uma tal situação de "ansiedade" e "terror" que ocorre um descontrole, que é novamente interpretado coletivamente como sendo devido à possessão, num ciclo interminável. Não se discute, é claro, o que diferencia tal "pensamento mágico" do sistema de crenças lógico-racionais da Medicina psiquiátrica, que no lugar de possessão interpreta cientificamente psicose. No entanto, esse questionamento passa a ficar a um passo de tal discussão quando desindividualiza a psicose, mesmo mantendo-a como psicose, sendo isto o que este artigo sugere: no fenômeno que a família "vê" possessão, explicando-o também como tal, o pensamento racionalista-psiquiátrico dos autores "vê" um transtorno essencializado por pensamento mágico coletivo e delírio individual (ou mesmo delírio compartilhado); assim como outra "cultura" poderia ver e atribuir outra interpretação. ${ }^{6}$ Claro que, neste trabalho, o poder da verdade universal é atribuído à Psiquiatria (com auxílio antropológico), a quem cabe a elucidação final - mas com bom senso suficiente, a ponto de não pretender explicar tudo.

Além das teorizações psicanalíticas sobre a loucura, e dessa última teorização antropológica, dois outros artigos buscam algum nível de compreensão existencial da "esquizofrenia", partindo do sujeito diagnosticado como esquizofrênico no molde psiquiátrico tradicional. Ambos fazem um relato de caso em que se tenta, através do relato de si mesmo do esquizofrênico, compre-

6 O ato aqui designado como ver se refere a uma ação em que, simultaneamente, a percepção de um fenômeno da realidade se une a uma interpretação essencialista que coloca aquele fenômeno em um contexto que o explica, algo que foi chamado por Merleau-Ponty (1999) de "fé perceptiva". 
Alguns Conceitos de Loucura entre a Psiquiatria e a Saúde Mental: Diálogos entre os Opostos?

ender seu ser-no-mundo, as diversas relações do indivíduo com alguns níveis de inter-relação (como sujeito de um grupo familiar, de um grupo social, etc.). Um desses artigos cita como método orientador da análise a teoria semiótica (Humerez, 2000). Outro, a Fenomenologia existencial (Rovaletti, 1999).

Humerez (2000) argumenta o seguinte, após um relato tradicional de uma história de vida em que a paciente num dado momento enlouquece:

Pode-se dizer que o adoecer mental é a consequiência da destruição da trama de sustentação da continuidade do eu e devido a isto dissolve-se sua vivência de existir. Concretiza-se um vazio insuportável e, ao buscar saídas, constitui-se uma nova trama de sustentação e continuidade, e constrói-se um novo projeto, mas, desta vez, pouco ou nada compartilhado com os demais, pois a pessoa poderá armar um eu fechado e solitário, desestruturando-se a leitura prospectiva de sua ação. (Humerez, 2000, p. 60)

A partir daí, a paciente luta para se manter inserida nos seus grupos sociais, mas "a internação psiquiátrica é reconhecida como determinante do rompimento com o grupo social" (Humerez, 2000). A história de vida da paciente passa a ser "relacionada fortemente pelo quadro clínico do transtorno mental pelo qual foi diagnosticada. Pode-se inferir que tal adoecer cristaliza o personagem louco. A normalidade parece representar o fenômeno de rejeição da loucura" (apontar a página citada) Desse modo, esse processo existencial da loucura é descrito como tendo duas essências destruidoras da subjetividade, o "adoecer mental" e a "internação psiquiátrica".

Em outro artigo, citando um filósofo existencialista (Martin Heidegger), Rovaletti (1999) afirma uma teorização sobre o "ser" como modo de transcender a psicopatologia psiquiátrica restrita à percepção individualizada da mente ou ao psicológico pessoal:

A experiência esquizofrênica se reduz a um acumulado de escombros e a um agregado anárquico de sintomas, ou é uma existência dotada de sentido, porém diversa da nossa? A metamorfose psicótica não se limita a arrastar consigo uma sintomatologia clínica, aquela leitura da ordem do ter, mas que modifica o modo de ser e de participar no mundo de todo paciente. (Rovaletti, 1999. pp. 338-339)

Já um outro artigo analisado (Dorr, 2002) faz uma defesa da Fenomenologia filosófica, em contrapartida ao que a Psiquiatria anglo-saxã tem 
chamado de Fenomenologia - uma mera "descrição de sintomas" -, e também a defesa de uma "terapêutica hermenêutica" para a esquizofrenia. Dorr (2002) estabelece os fenômenos da psicose dentro de um campo de subjetividade em que qualquer generalização (diagnóstico-descritiva inclusive) seria uma apropriação ilusória sobre um fenômeno que é estritamente inacessível ao outro na relação dual; exceto pela Fenomenologia transcendental que ele defende como sendo possível para compreender e dar a devida interpretação ao fenômeno totalmente subjetivo da esquizofrenia. Nesse percurso, portanto, Dorr leva a relativização ontológica do conhecimento a um ponto mais radical do que a relativização antropológica feita por Fierro Urresta et al. (2003), apresentada anteriormente. Dorr considera a concepção psiquiátrica da psicose, tanto a descritiva quanto a essencialista, como interpretações doutrinárias que não carregam qualquer verdade universalizável em si mesmas:

Sabemos que nas psicoses funcionais ou endógenas não há substrato que fundamente o diagnóstico.... Os diagnósticos operacionais da psiquiatria anglo-saxã foram criados com intento de superar a subjetividade dos diagnósticos psiquiátricos tradicionais, mas isto é uma ilusão, porque os sintomas em psiquiatria não são “coisas" nem "substâncias", não são "entes em si", e sim complexas experiências subjetivas do paciente, expressas em uma linguagem ambígua e que somente a experiência do entrevistador pode qualificar adequadamente (Dorr, 2002).

Essa afirmação de Dorr sintetiza de forma mais clara as afirmações dos artigos que agrupamos nesse tema. Embora a maioria dos artigos rejeite a teorização psiquiátrica tradicional (no que ela explica da loucura, psicose ou esquizofrenia como doença orgânica), apenas o fazem até o ponto de afirmarem outra concepção essencialista em seu lugar, e sobre o mesmo objeto perceptivo (esquizofrenia ou psicose) definidos pela Psiquiatria tradicional. Em parte, isso também acontece nesse artigo de Dorr (2002), já que ele afirma que a experiência da loucura é inacessível a qualquer explicação teórica essencialista universalizante, tanto em essência naturalista (biológica) quanto psicológica, porém defendendo uma clínica de psicóticos ou loucos - o que já é um reconhecimento perceptivo apriorístico -, na qual a experiência com o terapeuta seria a única possibilidade de resgatar o psicótico de sua total solidão ontológica. 
Alguns Conceitos de Loucura entre a Psiquiatria e a Saúde Mental: Diálogos entre os Opostos?

A par tal contradição, para Dorr, generalizações teóricas são construções lingüísticas que apenas servem para os que as constroem explicarem para si mesmos os fenômenos, e não para uma auto-elucidação do que está sendo percebido como fenômeno da loucura para o louco. Para tanto, aponta uma clínica que não generalize teorias e diagnósticos, já que ambos não carregam qualquer verdade generalizável. Segundo ele, a impossibilidade de o profissional experenciar o fenômeno que o esquizofrênico vivencia provocaria o erro de se afirmarem sintomas como "afetividade plana" ou "falta de contato", pois diante de tal sujeito "nós sentimos falta de uma certa comunidade primordial.... Nossas emanações não concordam, mas estão no mesmo tom", enquanto as "nossas" com as do "louco" estariam em tons essencialmente diferentes. Não haveria, desse modo, psicopatologias, lapsos irracionais ou uma estrutura inconsciente na individualidade psicológica do paciente a torná-lo secundariamente estranho e inacessível. A própria estranheza e inacessibilidade ontológica seria a essência da loucura, por tratar-se de diferença de experiência subjetiva do mundo que coloca o psicótico em uma vivência hermenêutica (solipsista), para os que o cercam, os quais têm entre si maior compartilhamento de experiências e significados existenciais. Assim, Dorr defende as "terapias hermenêuticas" como única forma de acesso ao esquizofrênico, com o fim de compreendê-lo (construindo uma compreensão compartilhada) naquilo que ele revela e constrói de si na presença do terapeuta. E sem ter a possibilidade de explicar nada do paciente que sirva a outros sujeitos, a não ser à própria concepção de uma experiência hermenêutica da loucura.

\section{Considerações finais}

Fundamentalmente, há uma grande discordância entre os conceitos considerados mais tipicamente da Psiquiatria e os que aqui consideramos pertencentes à Saúde Mental (os quais, aliás, não guardam uma unidade conceitual tão uniforme quanto nas publicações psiquiátricas). A síntese que fizemos da conceituação de loucura na Psiquiatria nos aponta que nessa área ela está sendo afirmada como doença médica (somática ou orgânica) de origem genética. Na Saúde Mental, alguns poucos artigos fazem uma rejeição explícita da essência biológica na explicação psiquiátrica da loucura, embora seja quase unânime a rejeição de que o fenômeno da loucura se reduza a esse biologi- 
cismo e à sua terapêutica com tratamentos químicos. Por outro lado, há uma crítica contumaz por parte da Saúde Mental às práticas de institucionalização feitas com o alvará científico e social (institucional e legal) da doença mental. É possível observar em alguns artigos que boa parte do fenômeno da loucura (principalmente seu aspecto social) é afirmada como consequiência das internações hospitalares, resultando naquilo que, no indivíduo, é percebido como doença. O significado de doença terminaria por ser uma espécie de alvará científico para a intolerância e a estigmatização social, cujas conseqüências são os próprios fenômenos reificados como da loucura enquanto doença.

A concepção de loucura na Saúde Mental, tem, portanto, uma abrangência maior do fenômeno, que inclui tanto o fenômeno social da estigmatização quanto o que pode haver de essencialmente individual na loucura, componente que na Psiquiatria é entendido como biológico, e na maior parte dos artigos de Saúde Mental aqui analisados é visto como psicológico, restrito ao indivíduo, a suas estruturas psíquicas internas, ou, às vezes, como um psicológico individual que resulta do coletivo ou do social, em uma concepção de psíquico para além de um resultado do funcionamento biológico, como acontece com freqüência na Psiquiatria. Isso faz com que a teorização da Psiquiatria, ao explicar a loucura apenas como uma doença biológica, seja vista em boa parte da Saúde Mental como um incremento do fenômeno social da loucura, uma explicação que legitima sua estigmatização na vida coletiva, e não necessariamente uma explicação científica válida.

A grande distância de concepções que se forma entre Psiquiatria e Saúde Mental se estabelece na conceituação do reconhecimento do que vem a ser loucura. Na Psiquiatria, esse reconhecimento se estabelece sendo o diagnóstico uma descrição da doença, na Saúde Mental, entende-se que há um rótulo social que incrementa e legitima a exclusão (pelo poder dado à voz da ciência médica), principalmente se esse rótulo for a base significativa para a internação involuntária legalizada, ratificando em definitivo a estigmatização social da loucura.

Já a Psiquiatria entende a loucura como uma doença orgânica, que recebe um nome - esquizofrenia - como método de identificá-la e estabelecer, então, um tratamento farmacológico que a elimine do comportamento e do pensamento do indivíduo. Esse ato humanista médico resultaria em diminui- 
Alguns Conceitos de Loucura entre a Psiquiatria e a Saúde Mental: Diálogos entre os Opostos?

ção da exclusão social, já que a Psiquiatria vê essa exclusão como um fenômeno apenas social (de senso comum não esclarecido) de intolerância, desencadeado sobre os sintomas de uma doença, os quais seriam efeitos do orgânico em funcionamento anormal - sintomas que seriam esbatidos no caso de um tratamento médico eficiente a ser alcançado. A Psiquiatria, portanto, entende que pode atingir a exclusão do louco via tratamento químico para uma doença tida como do cérebro, e de origem genética, sendo que uma Psicologia do louco, seus comportamentos e a intolerância social que recai sobre ele resultariam de uma alteração neuroquímica; patologia orgânica que se associaria a uma sociedade intolerante, que deveria ser esclarecida sobre tais pensamentos e comportamentos se deverem a uma doença, e não a outros motivos -como atitudes propositadamente imorais ou não-humanas que configurariam os atos do louco, os quais são, do ponto de vista psiquiátrico, a razão da intolerância social e da exclusão. Desse modo, a Psiquiatria acredita que o esclarecimento sobre o caráter nosológico da loucura já reduziria o estigma e a exclusão social do louco, principalmente se associado a um tratamento médico efetivo.

A concepção teórica da Saúde Mental percebe a loucura essencialmente como um fenômeno de intolerância e exclusão da vida social, em que surge um rechaço do louco por ele ser visto como doente mental, o que conduz a uma internação hospitalar mesmo contra sua vontade, com o fim de ser isolado. A internação é vista como o auge da exclusão social, e não um meio contrário à intolerância. A Psiquiatria entra nessa concepção de loucura como o agente carcerário da exclusão, fornecendo o rótulo e a explicação que autoriza que a sociedade exerça seu rechaço daquele que considera imoral ou estranho. Mais do que isso, a Psiquiatria instrumentalizaria essa intolerância social dando-lhe um aparato de exclusão que ela própria não teria: a interdição hospitalar e civil com autoridade outorgada ao médico com base em seu discurso humanista.

A Saúde Mental percebe, portanto, aquilo que a Psiquiatria explica com o nome de uma doença (ou a própria designação geral de doença mental) como um rótulo e uma explicação que sentenciam a exclusão física do louco do convívio social. O que, sem dúvida, é reforçado pela rejeição explícita que a visão psicológica dos artigos analisados tem sobre a explicação biológica, considerando-a inautêntica. 


\section{Francisco da Costa Júnior e Marcelo Medeiros}

Há, portanto, de modo claro, duas concepções de mundo nas quais os artigos aqui analisados se inserem: a psiquiátrica, claramente naturalista; e a da Saúde Mental, que se mostra pretensamente anti-naturalista, mais psicológica (embora, em boa medida, de uma Psicologia também naturalista) e com uma visão de loucura em que se concebe o ser humano como ser coletivo, social ou cultural. Na Saúde Mental, a autonomia individual do sujeito é determinada pelo coletivo, enquanto na Psiquiatria, no tocante ao louco como doente mental, é determinada por sua estrutura orgânica. Na Psiquiatria se atribui aos pensamentos e comportamentos considerados loucos uma origem biológica sobre a qual o sujeito não tem autonomia, desautorizando qualquer intencionalidade humana que o mesmo tenha sobre seus atos. Poder sobre os atos que, não pertencendo mais ao sujeito, são controlados por técnicas, tanto asilares quanto químicas, de contenção, ou com vistas à restituição desse poder - que ele perdeu para as forças advindas de um orgânico fora da normalidade natural. Enquanto isso, na Saúde Mental se atribui o social (incluindo a própria Psiquiatria e suas técnicas para controle da loucura) como determinante das ações (reações, portanto) do louco em busca de sua autonomia subjetiva desautorizada. Também na Saúde Mental se percebe o louco desautorizado em seus atos, mas pelos agentes sociais à sua volta, principalmente pela instituição psiquiátrica, que transfere para o orgânico doente a autoria de suas ações.

A única intersecção mais clara entre esses dois mundos dá-se no campo psicológico, pois este pode ser concebido mais ao modo das ciências naturais, como uma doença, só que no lugar de alterar o funcionamento do puramente orgânico, afetaria o modo de funcionar do puramente psíquico. Do mesmo modo, no pólo mais social da Saúde Mental, o psíquico pode vir a ser o locus onde o social consubstancia em ações e pensamentos individuais a origem social da loucura.

Uma outra intersecção entre essas duas concepções de mundo se dá pelo fato de a loucura, em todos os artigos analisados, somente ser reconhecida como fenômeno perceptivo, limitada ao indivíduo, e com os conceitos perceptivos que a Psiquiatria construiu ao longo de sua história (psicose e esquizofrenia). Contudo, sendo, no pólo mais sociológico da Saúde Mental, uma loucura percebida no indivíduo mas concebida como de origem extra-individual, social; e no pólo mais naturalista da Psiquiatria, sendo percebida no indi- 
Alguns Conceitos de Loucura entre a Psiquiatria e a Saúde Mental: Diálogos entre os Opostos?

víduo mas concebida com origem no biológico (o que é, também, embora de um outro modo, extra-individual, em relação à sua autonomia como sujeito).

Também comum a todas essas concepções há a explicação lógico-racional que aponta o que é e qual a origem da loucura para além do louco como agente produtor de si mesmo, de seus próprios significados. A exceção encontrada foi o artigo de Otto Dorr (2002), que afirmou a loucura como experiência hermenêutica, restrita a uma experiência que apenas o próprio louco pode construir, inclusive em termos de auto-explicação (de significados) - embora esse autor tenha afirmado que essa auto-explicação necessite ser constituída em ato terapêutico.

Não há, portanto, nas duas concepções de mundo mais comuns que envolvem a loucura, a naturalista e a sociológica, bem como nesta última (de Dorr), a hermenêutica, grande confluência teórica a possibilitar diálogos entre o mundo psiquiátrico e o da Saúde Mental reformista. Pelo contrário, parece mesmo que suas concepções de ser humano são mutuamente excludentes, há um choque de "culturas" ou de concepções de mundo, com alguns poucos pontos de diálogo. Dito de outro modo e utilizando a linguagem filosófica, também as teorizações dessas duas áreas tornaram-se elas próprias hermenêuticas ou mesmo ontologicamente distintas, estranhas e inacessíveis uma à outra.

Costa Jr., F., \& Medeiros, M. (2007). Some concepts of madness between traditional Psychiatry and Mental Health: Dialogues among the opposites? Psicologia USP, 18(1). 57-82.

\begin{abstract}
This article presents part of the results of a bibliographical research on conceptions of madness in Psychiatry and in Mental Health. Publications in the LILACS database between 1999 and 2004 have been analyzed. The amplest research was conducted by thematic areas and, in the present article we have concentrated on two of them: publications that confirm conceptions of madness as medical illnesses; and publications that define madness by explicitly rejecting the psychiatric conception of madness, discussing madness with other conceptions which maintain a dialogue with the percipient objects (diagnostic descriptions) which
\end{abstract}




\section{Francisco da Costa Júnior e Marcelo Medeiros}

Psychiatry has conceived throughout its history. These more recent conceptualizations, which are sometimes called alternative, but are in fact previous to the current conceptions of madness in Psychiatry (by considering it a genetic disorder, for instance), pointing to theoretical constructs that confirm a conception of mind, of the psychological, from a more individualized perspective to something resulting from social inter-relations. Finally, we discuss how these conceptions of madness are related to world conceptions (and, consequently, conceptions of the human being) that are distinct and even exclude each other, with a more naturalistic world vision in Psychiatry and a more sociological and collectivist vision in Mental Health, which have both been clashing beyond the scientific problems concerning madness.

Index terms: Madness. Mental health. Psychiatry.

Costa Jr., F., \& Medeiros, M. (2007). Certains concepts de folie entre la Psychiatrie e la Santé Mentale: dialogues entre les opposés? Psicologia USP, 18(1). 57-82.

Résumé: On a analysé des publications sorties entre 1999 et 2004 constituantes de la base de données LILACS (Littérature Latino-américaine et des Caraibes en Sciences de la Santé). Pour cette investigation, deux régions thématiques sont mises en relief: les publications qui affirment les concepts de la folie comme maladie médicale et les publications qui soutiennent la conception psychiatrique de folie. Ces conceptualisations, qui sont appelées alternatives mais qui fréquemment sont antérieur aux concepts courants soutenus pour la Psychiatrie, portent des idées théoriques qui raffirment une conception de l'esprit (le psychologique) autant individuellement que collectivement. De toute façon, ces concepts de folie sont mentionnés dans différentes conceptions du monde: l'une est plus naturaliste, formulée dans le domaine de la Psychiatrie; l'autre est plus sociologique et collectiviste, formulée dans le domaine de la Santé Mentale, et donc elles rivalisent au-delà du problème théorique concernant la folie.

Mots clés: Folie. Santé mentale. Psychiatrie. 
Alguns Conceitos de Loucura entre a Psiquiatria e a Saúde Mental: Diálogos entre os Opostos?

\section{Referências}

Adad, M. A., Castro, R., \& Mattos, P. (2000). Aspectos neuropsicológicos da esquizofrenia. Revista Brasileira de Psiquiatria, 22(1), 31-34.

Alho Filho, J. L. (2000). Delírio e intuição. Campinas: Universidade de Campinas.

Amarante, P. D. C. (1994). O homem e a serpente: outras histórias para a loucura e a psiquiatria. Rio de Janeiro: Ed. Fiocruz.

American Psychiatryc Association. (2002). Manual diagnóstico e estatístico de transtornos mentais (DSM IV Tr.). Porto Alegre: Artmed.

Bardin, L. (2002). El análisis del contenido (3a ed). Madrid: Akal.

Basaglia, F. O. (1979). A psiquiatria alternativa: contra o pessimismo da razão, o otimismo da prática. São Paulo: Editora Brasil Debates.

Basile, L. F. H. (2000). Alterações eletrofisiológicas na esquizofrenia. Revista Brasileira de Psiquiatria, 22(1), 12-14.

Busatto Filho, G. (2000). A anatomia estrutural e funcional da esquizofrenia: achados de neuropatologia e neuroimagem. Revista Brasileira de Psiquiatria, 22(1), 9-11.

Bressan, R. A., \& Pilowsk,Y. L. S. (2003). Hipótese glutamatérgica da esquizofrenia. Revista Brasileira de Psiquiatria, 25(3), 177-183.

Bressan, R. A., Bigliani, V., \& Pilowsky, L. S. (2001). Neuroimagem de receptores D2 de dopamina na esquizofrenia. Revista Brasileira de Psiquiatria, 23(1), 46-49.

Cassirer, E. (2005). Ensaio sobre o homem: introdução a uma filosofia da cultura humana. São Paulo: Martins fontes.

Castoriadis, C. (1999). Feito e a ser feita: as encruzilhadas do labirinto V. Rio de Janeiro: DP\&A Editora.

Cooper, D. (1989). Psiquiatria e antipsiquiatria (2a ed.). São Paulo: Perspectiva.

Cordeiro Junior, Q., Junqueira, R., \& Vallada, H. (2001). Estudo de associação entre o polimorfismo serina-9-glicina do receptor dopaminérgico D3 e esquizofrenia. Arquivos de Neuro-Psiquiatria, 59(2A), 219-222.

Dias, M. K., \& Dalgalarrondo, P. (2001). Psicoses psicogênicas: do bouffée delirante à psiquiatria cultural. Jornal Brasileiro de Psiquiatria, 50(7/8), 247-254.

Dorr, O. (2002). El papel de la fenomenología en la terapéutica psiquiátrica con especial referencia a la esquizofrenia. Revista Chilena de Neuro-psiquiatria, 40(4), 297-306.

Elkis, H. (2000). A evolução do conceito de esquizofrenia neste século. Revista Brasileira de Psiquiatria, 22(Supl.1), SI23-SI26. 


\section{Francisco da Costa Júnior e Marcelo Medeiros}

Elkis, H., Kimura, L., \& Nita, L. M. (2001). Neuroimagem estrutural e psicopatologia: sintomas positivos e negativos e dilatação ventricular na esquizofrenia. Revista Brasileira de Psiquiatria, 23(Supl. 1), 19-23.

Fierro Urresta, M., Rueda, L., Abrahim, J., Garcya, E., Jaimes, L. A., \& Atuesta, J. (2003). Psicosis y sistemas de creencias. Revista Colombiana de Psiquiatria, 32(3), 281-292.

Freire, A. B. (1999). Considerações sobre a Letra: a psicose em questão. Psicologia Reflexão e Crítica, 12(3), 567-583.

Gattaz, W. F. (2000). Neuroquímica da esquizofrenia: papel dos fosfolípides. Revista Brasileira de Psiquiatria, 22(Supl.1), 5-8.

Gil, A. C. (2002). Como elaborar projetos de pesquisa (4a ed.). São Paulo: Atlas.

Gilbert, A. R., \& Keshavan, M. S. (2001). MRI structural findings in schizophrenia. Revista Brasileira de Psiquiatria, 23(Supl.1), 15-18.

Humerez, D. C. (2000). História de Hélia: referência existencial da esquizofrenia paranóide. Acta paulaulista de Enfermagem, 13(1), 55-65.

Kuhn, T. S. (2005). A estrutura das revoluções cientificas (9a ed.). São Paulo: Perspectiva.

Lara, D. R., \& Souza, D. O. (2001). Modelo de hipofunção adenossinérgica para esquizofrenia: interação entre os sistemas purinérgico, glutamatérgico e dopaminérgico. Revista de Psiquiatria Clínica, 28(3), 160-169.

Lima, I. V. M. (1999). Repetições CAG: candidatos na gênese das psicoses funcionais. Revista Brasileira de Psiquiatria, 21(supl. 2), 23-26.

Lopes, J. L. (2001). A psiquiatria na época de Freud: evolução do conceito de psicose em psiquiatria. Revista Brasileira de Psiquiatria, 23(1), 28-33.

Marchetti, R. L. (2000). Neuroimagem nas psicoses associadas à epilepsia. Revista de Psiquiatria Clínica: São Paulo, 27(3), 143-53.

Martins, F., Costa, A. C., \& Aquino, A. P. (1999). A referência e o pensamento psicótico. Psicologia Reflexão e Crítica, 12(2), 537-548.

Merleau-Ponty, M. (1999). O visível e o invisível (3a ed.). São Paulo: Perspectiva.

Messas, G. P. (2000). A genética da esquizofrenia, evidências de um século de estudos epidemiológicos. Jornal Brasileiro de Psiquiatria, 49(3), 51-60.

Organização Mundial de Saúde. (1993). Classificação de transtornos mentais e de comportamento da Cid-10: descrições clínicas e diretrizes diagnósticas. Porto Alegre: Artmed.

Ojopi, E. P. B., Gregorio, S. P., Guimaräes, P. E. M., Fridman, C., \& Dias Neto, E. (2004). O genoma humano e as perspectivas para o estudo da esquizofrenia. Revista Psiquiatria Clínica, 31(1), 9-18. 
Alguns Conceitos de Loucura entre a Psiquiatria e a Saúde Mental: Diálogos entre os Opostos?

Pessoti, I. (1999). Os nomes da loucura. São Paulo: Ed. 34.

Ramos, L. (2001). A psicoterapia das psicoses na visão de Jung. Arquivos Brasileiros de Psicologia, 53(1), 85-91.

Reis, C. A. M. (2000). Considerations about the diagnosis of childhood psychosis: A psychoanalytic approach. São Paulo: Psicologia USP, 11(1), 207-242.

Riquelme Véjar, R., \& Arancibia Vaccaro, C. (2002). Estructura intermedias en la comunidad: una estrategia psicodinámica de tratamiento de la psicosis. Psiquitria y Salud Mental, 19(1), 40-45.

Rovaletti, M. L. (1999). Esquizofrenia, sentido y sin-sentido. Revista Colombiana de Psiquiatria, 28(4), 335-543.

Sallet, P. C., \& Gattaz, W. F. (2002). Classificacao das psicoses endogenas de Karl Leonhard. Revista de Psiquiatria Clínica, 29(3), p.135-149.

Samaia, H. B., Moura, R. P., Vallada, H. P., Mari, J. de J., Simpson, A. J. G., \& Brentani, R. R. (1999). Nova variante do gene do priônio em uma família psicótica. Revista de Psiquiatria. Clínica, 26(3), 72-75.

Santos, M. A. (1999). A constituição do mundo psíquico na concepção winnicottiana: uma contribuição à clínica das psicoses. Psicologia Reflexão e Crítica, 12(3), 603-625.

Silva, A. A., Polanczyk, A. S., \& Millán, T. (2000). Psicose puerperal: uma revisão. Revista Científica AMECS, 9(2), 45-49.

Snow, C. P. (1995). As duas culturas e uma segunda leitura. São Paulo: EDUSP.

Soares-Weiser, K., Weiser, M., \& Davidson, M. (2003). Uso de maconha na adolescência e risco de esquizofrenia. Revista Brasileira de Psiquiatria, 25(3), 131-132.

Souza, G. F. J. (1999). Desdiferenciação simbólico-afetiva: um modelo teórico para as psicoses esquizofrênicas. Psiquiatria Biológica, 7(1), 19-30.

Souza, R. O., Marmorato, P. G., Castel, S., \& Gattaz, W. F. (1999). Psicose induzida por ISRS em paciente com alterações cerebrais. Revista de Psiquiatria, 26(3), 90-91.

Stone, M. H. (1999). A cura da mente: a história da psiquiatria da Antigüidade até o presente. Porto Alegre: Artmed.

Sucar, D. D., Sougey, E. B., \& Brandao Neto, J. (2002). Surto psicótico pela possível interação medicamentosa de sibutramina com finasterida. Revista Brasileira de Psiquiatria, 24(1), 30-33.

Szazs, T. S. (1978). Esquizofrenia: o símbolo sagrado da psiquiatria. Rio de Janeiro: Zahar.

Vallada Filho, Homero, P., \& Samaia, H. (2000). Esquizofrenia: aspectos genéticos e estudos de fatores de risco. Revista Brasileira de Psiquiatria, 22(Supl. 1), 2-4. 


\section{Francisco da Costa Júnior e Marcelo Medeiros}

Villares, C. C., Redko, C. P., \& Mari, J. J. (1999). Concepções de doença por familiares de pacientes com diagnóstico de esquizofrenia. Revista Brasileira de Psiquiatria, 21(1), 36-47.

Witton, J., \& Murray, R. M. (2004). Loucura do baseado revisitada: maconha e psicose. Revista Brasileira de Psiquiatria, 26(1), 2-3.

Recebido em: 30/06/2006

Aceito em: $7 / 08 / 2006$ 